\title{
Enzymatic Activity Prediction Using Time-Domain Nuclear Magnetic Resonance (TD-NMR) and Multivariate Analysis: A Case Study Using Cassava Roots
}

\author{
Josilei da Silva Ferreira ${ }^{1}$ Tiago Bueno Moraes $^{2} \cdot$ Luiz Alberto Colnago $^{3}$. \\ Fabíola Manhas Verbi Pereira ${ }^{1}$ (D)
}

Received: 18 December 2017 / Revised: 14 February 2018 / Published online: 26 February 2018 (C) Springer-Verlag GmbH Austria, part of Springer Nature 2018

\begin{abstract}
Time-domain nuclear magnetic resonance (NMR) has been widely used in food science. In this work, we demonstrate that the NMR decay obtained with the Carr-Purcell-Meiboom-Gill (CPMG) sequence can be used to estimate the peroxidase activity (PA) in cassava roots. This enzyme has been involved in post-harvest physiological deterioration (PPD), which limits the storage of fresh cassava to a few days. Cassava is a staple food for almost one billion people in tropical areas in Americas, Africa and Asia. A multivariate method using CPMG data and reference values of PA from a standard biochemical assay was built with 216 measurements for non-refrigerated and refrigerated samples of cassava roots. The figures of merit of the global partial least squares model using both types of roots showed a 0.06

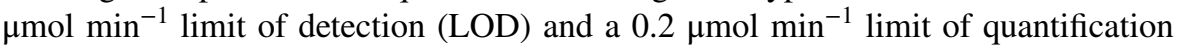
(LOQ) for PA, with 0.4 [intensity (a.u. $) /\left(\mu \mathrm{mol} \mathrm{min}^{-1}\right)$ ] sensitivity and a standard

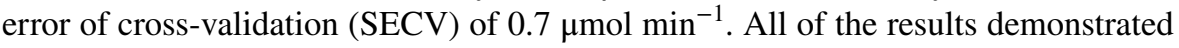
that TD-NMR has the potential to predict PA in cassava roots that is indicative of the PPD problem.
\end{abstract}

\section{Introduction}

Time-domain nuclear magnetic resonance (TD-NMR) has been used in food quality control and quality assurance for more than five decades. However, only in the last

Fabíola Manhas Verbi Pereira

fabiola@iq.unesp.br

1 Instituto de Química de Araraquara, Universidade Estadual Paulista (UNESP), Araraquara, São Paulo 14800-060, Brazil

2 Instituto de Física de São Carlos, Universidade de São Paulo, Av. Trabalhador São-carlense 400, São Carlos, São Paulo 13566-590, Brazil

3 Embrapa Instrumentação, São Carlos, São Paulo 13560-570, Brazil 
two decades has TD-NMR expanded its applications to basic food studies, including water status, water compartmentalization and molecular mobility, using relaxation and diffusion measurements [1-3]. Transverse relaxation $\left(T_{2}\right)$ measurements have been performed with the Carr-Purcell-Meiboom-Gill (CPMG) pulse sequence, and measurements of longitudinal relaxation time $\left(T_{1}\right)$ or the $T_{1} / T_{2}$ ratio have been performed using continuous wave free precession (CWFP) pulse sequences [1-5].

To the best of our knowledge, there is no application of TD-NMR to predict enzyme activity in foodstuff. Therefore, we propose a rapid and simple method to monitor peroxidase activity (PA) in cassava using a benchtop time-domain NMR relaxometer. The method is based on a multivariate regression model with exponential decay of the NMR signal measured via the CPMG pulse sequence as the independent variable and PA measured with a standard biochemical assay as the dependent variable.

Cassava, also known as manioc or tapioca (Manihot esculenta Crantz), is a staple food for almost a billion people living in tropical areas of Africa, Latin America, Oceania and Asia [6-8]. Cassava roots have been considered the "food for the poor", comprising more than $80 \%$ of starch [6] and are an important food source in tropical areas, including sub-Saharan countries, due to drought resistance and the ability to grow in marginal land [6, 7, 9]. Cassava is also cultivated in these areas because it produces approximately ten times more starch per unit area than most of the cereals $[9,10]$.

Despite the high agronomical productivity, cassava production is constrained by biotic and abiotic stresses when compared with other carbohydrate sources such as maize, wheat, rice and potato. The major cassava post-harvest constraint is the short life of fresh roots, limiting storage to a few days. Compared to potato tuber, fresh cassava roots deteriorate shortly after harvesting due to the post-harvest physiological deterioration (PPD) process that is induced by wounds suffered during harvesting and handling. PPD reduces cassava eating and processing quality; specifically, it takes a longer time to cook and acquires an unpalatable bitter taste, lower elasticity and unattractive appearance. PPD is a complex process involving changes in gene expression and environmental factors. The wounds in the roots trigger an oxidative burst that changes the activity of oxidative enzymes such as peroxidases, converting phenols into tannins $[6,7]$. The oxidative trigger is supported by the fact that oxygen exclusion, by immersion in water, low temperature or antioxidant compounds can eliminate or minimize the PPD process [7].

Therefore, a rapid, simple and non-destructive NMR method to monitor PA in cassava roots can be a highly practical alternative approach to the standard biochemical assay, which is laborious, time consuming and destructive and requires chemical reagents and specialized professionals $[11,12]$.

\section{Methods}

\subsection{Sampling}

Cassava roots, non-refrigerated (samples $\mathrm{N}$ ) and stored at room temperature or peeled and refrigerated at $10-12{ }^{\circ} \mathrm{C}$ (samples $\mathrm{R}$ ), were purchased locally. The $\mathrm{N}$ 
root samples were washed to remove soil and other impurities, dried with absorbent paper and peeled. The $\mathrm{R}$ samples had no need for cleanup procedure. None of the samples showed any damage or deterioration. In the case of industrialized $\mathrm{R}$ products, the expiration date was appropriate during the time of the tests. Subsequently, the $\mathrm{N}$ and $\mathrm{R}$ samples were milled with a domestic food chopper (Black \& Decker, Uberaba, MG, Brazil). The $\mathrm{N}$ and $\mathrm{R}$ samples were fractionated in 24 subsamples of $10 \mathrm{~g}$ each. The subsamples were exposed to air and subsequently analyzed by TDNMR and the enzymatic assay at time $0,24,48$ and $72 \mathrm{~h}$.

\subsection{TD-NMR Measurements}

The TD-NMR analyses were carried out at $22{ }^{\circ} \mathrm{C}$ in a $0.27 \mathrm{~T}\left(11.3 \mathrm{MHz}\right.$ for $\left.{ }^{1} \mathrm{H}\right)$ benchtop SLK200 Spinlock instrument (Spinlock Magnetic Resonance Solutions, Cordoba, Argentina) using a probe $32 \mathrm{~mm}$ in diameter and $32 \mathrm{~mm}$ in height. The measurements were performed using the standard CPMG sequence to obtain the exponential decay signal that is governed by the transverse relaxation time $\left(T_{2}\right)$. The sequence used $\pi / 2$ and $\pi$ of 11.56 and $19.6 \mu \mathrm{s}$, respectively, an echo time of $600 \mu \mathrm{s}$, four scans and 1500 echoes.

\subsection{Reference Method for Enzymatic Activity}

Just after the TD-NMR analyses, the subsamples were used to measure the enzymatic activity by a standard biochemical assay [12]. This method used the reaction between guaiacol $\left(\left(\mathrm{CH}_{3} \mathrm{O}\right) \mathrm{C}_{6} \mathrm{H}_{4} \mathrm{OH}\right)$ and hydrogen peroxide $\left(\mathrm{H}_{2} \mathrm{O}_{2}, 30 \%\right.$; Synth $)$ in the presence of enzymatic extracts of the milled cassava roots.

The extractions were performed at $10{ }^{\circ} \mathrm{C}$, using $50 \mathrm{~mL}$ of buffer solution containing $0.1 \mathrm{~mol} \mathrm{~L}^{-1}$ potassium phosphates $\left(\mathrm{KH}_{2} \mathrm{PO}_{4}\right.$ and $\mathrm{K}_{2} \mathrm{HPO}_{4}$; Synth, Diadema/SP, Brazil (pH 7.5) and $200 \mathrm{mg}$ of polyvinylpyrrolidone $\left.\left(\mathrm{C}_{6} \mathrm{H}_{9} \mathrm{NO}\right)_{n}, \mathrm{PVP}-10\right)$; Sigma Aldrich, Saint Louis, MO, USA. The milled cassava sample and the extraction solution were mixed using a domestic food chopper. Afterward, the suspensions were filtered using gauze. Then, the supernatant that contains the enzymatic extract of peroxidases was separated using an 80-2BU centrifuge (Centrilab, Monte Alto, SP, Brazil) for $30 \mathrm{~min}$ at $3800 \mathrm{rpm}$.

The biochemical assay was performed with $500 \mu \mathrm{L}$ of enzymatic extract from cassava, $500 \mu \mathrm{L}$ of $1.5 \mathrm{mmol} \mathrm{L}^{-1}$ guaiacol (98\%; Sigma Aldrich), $500 \mu \mathrm{L}$ of $1.5 \mathrm{mmol} \mathrm{L}^{-1}$ hydrogen peroxide (30\%; Synth) and $1500 \mu \mathrm{L}$ of $0.1 \mathrm{~mol} \mathrm{~L}^{-1}(\mathrm{pH}$ 7.5 ) potassium phosphate buffer solution. The solutions were stirred manually, and after $4 \mathrm{~min}$ the reactions were monitored at $470 \mathrm{~nm}$ (the maximum absorbance for tetraguaiacol, $\varepsilon_{470}=26.6 \mathrm{mmol}^{-1} \mathrm{~L} \mathrm{~cm}^{-1}$ ) using a $1 \mathrm{~cm}$ optical length cuvette in a Femto 600 plus instrument (Femto Ind. e Com. de Instrumentos, São Paulo, SP, Brazil) to measure PA. The calculations of PA were based on the definition that one unit of peroxidase is equal to the amount of enzyme that yields $1 \mu \mathrm{mol}$ $\mathrm{L}^{-1}$ tetraguaiacol per minute. The reactions and spectrophotometric measurements were performed at $22{ }^{\circ} \mathrm{C}$. 


\subsection{Data Evaluation}

Multivariate analyses were performed using the partial least squares (PLS) algorithm available in Pirouette 4.5 rev. 1 (Infometrix, Bothell, WA, USA). To determine the composition of the samples in the training and validation datasets, the Kennard-Stone algorithm was applied [13]. The TD-NMR decays data were used as independent variables, and the measured values of PA using the reference method for enzymatic activity were used as dependent variable. The goal was to estimate the enzymatic activity of two types of cassava (non-refrigerated and refrigerated) exposed to air environments using reference values from a standard biochemical assay and signals of TD-NMR combined with PLS.

\section{Results and Discussion}

Figure 1 shows the values of peroxidase activity (PA) in non-refrigerated (N) and refrigerated (R) samples at $0,24,48$ and $72 \mathrm{~h}$ after milling. For the $\mathrm{N}$ and $\mathrm{R}$ samples at time 0 , the means and standard deviations were $3.9 \pm 1.2$ and $2.7 \pm 0.73$, respectively. The PA for the $\mathrm{N}$ samples decays to $2.9 \pm 1.2,1.8 \pm 0.9$ and $1.8 \pm 1.4$ for 24, 48 and $72 \mathrm{~h}$, respectively. A similar monotonic tendency was observed for the $\mathrm{R}$ samples with the PA decay to $1.6 \pm 0.18,1.5 \pm 0.23$ and $1.4 \pm 0.16$, for 24,48 and $72 \mathrm{~h}$, respectively. It is relevant to emphasize that the refrigerated samples were purchased from three different markets, with differences in expiration dates. Therefore, Fig. 1 shows that the PA was higher in the $\mathrm{N}$ samples than in the R samples and that the upper magnitude for activity was observed in the $\mathrm{N}$ sample at time 0 (N0). The higher SD values for cassava samples non-refrigerated than for the refrigerated samples is associated with higher variability of PA. A possible explanation for these

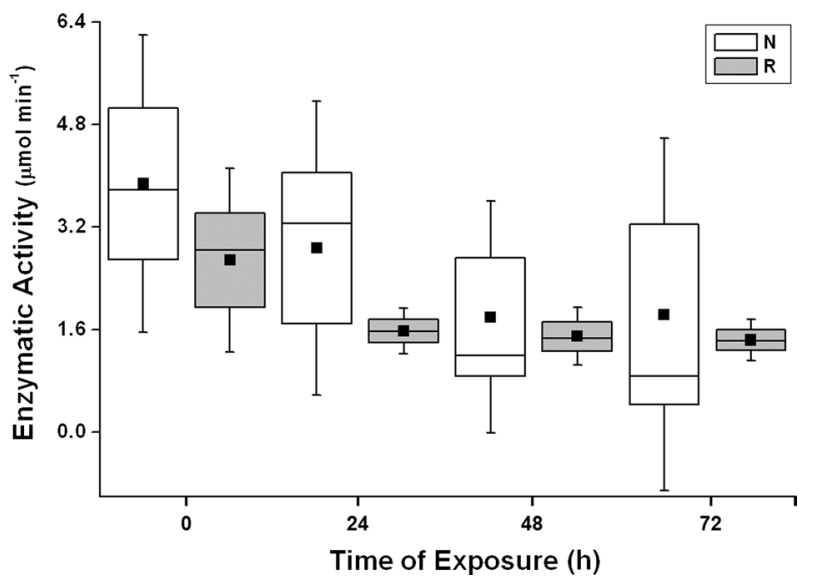

Fig. 1 Box plots for enzymatic activity measured using a standard biochemical assay for non-refrigerated $(\mathrm{N})$ and refrigerated $(\mathrm{R})$ commercial cassava samples 
differences is that the $\mathrm{R}$ roots are normally treated with sodium or potassium chlorides that have been used as preservatives in refrigerated cassava [14].

Figure 2a, b shows the typical normalized CPMG decays for the $\mathrm{N}$ and $\mathrm{R}$ samples, respectively, at time 0 and after $72 \mathrm{~h}$. In both plots, the CPMG was much shorter for samples after $72 \mathrm{~h}$ of experiments and showed lower PA values than at time 0 , as shown in Fig. 1.

Figure $3 \mathrm{a}, \mathrm{b}$ shows the inverse Laplace transform relaxation distribution of the CPMG decays of the $\mathrm{N}$ and $\mathrm{R}$ samples of Fig. 2a, b, respectively. All samples showed three $T_{2}$ peaks. In Fig. 3a, the black line shows a small peak at $2.8 \times 10^{-3} \mathrm{~s}$ and two intense peaks at $3.9 \times 10^{-2}$ and $1.9 \times 10^{-1} \mathrm{~s}$ for the N0 sample with a PA of $4.1 \mu \mathrm{mol} \mathrm{min}{ }^{-1}$. The violet line in Fig. 3a shows the relaxation distribution of the sample with $2.0 \mu \mathrm{mol} \mathrm{min}{ }^{-1} \mathrm{PA}$, with a broad peak at $8.5 \times 10^{-4}$, an intense peak at $2.0 \times 10^{-2}$ and a small peak at $2.3 \times 10^{-1} \mathrm{~s}$. The relaxation profile of the $\mathrm{R}$ samples
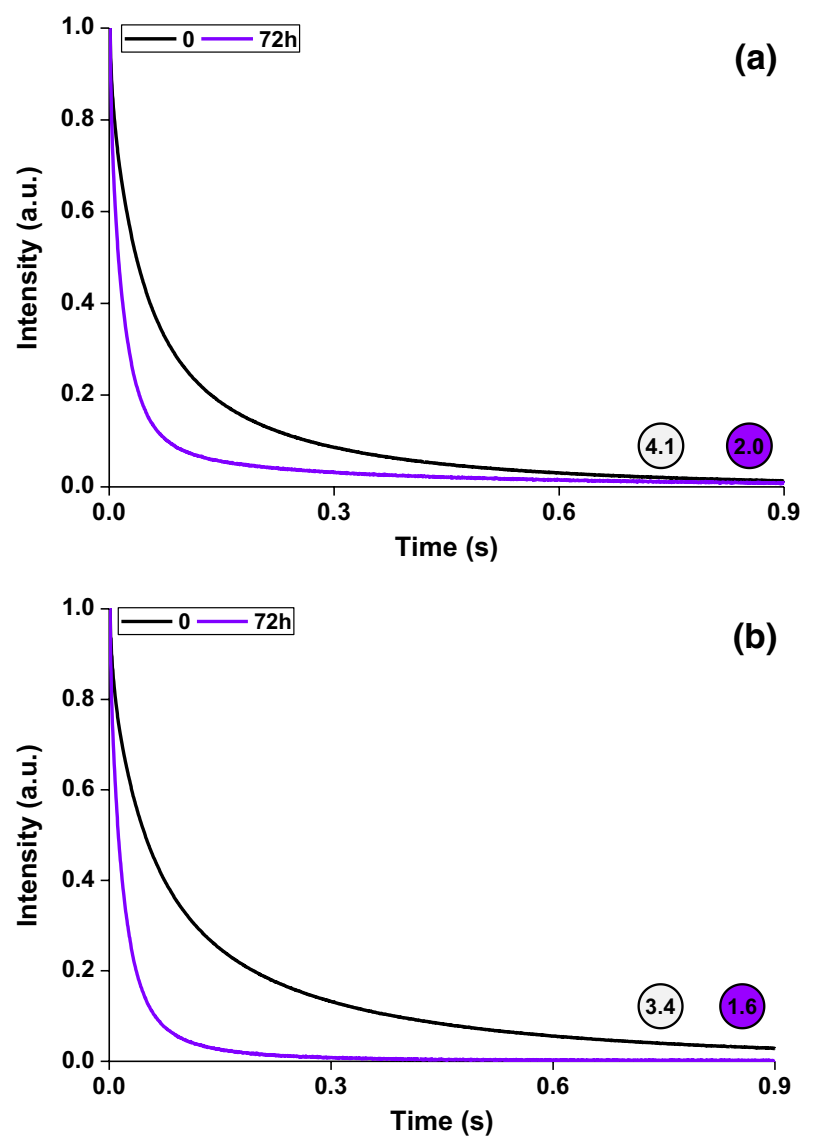

Fig. 2 Transverse relaxation time $\left(T_{2}\right)$ from CPMG signals representing non-refrigerated samples (time 0 ) and after $72 \mathrm{~h}$ of air environment exposure for a non-refrigerated (N0) and b refrigerated (R) samples. The peroxidase activity (PA) values in $\mu \mathrm{mol} \mathrm{min}^{-1}$ are denoted by circles 

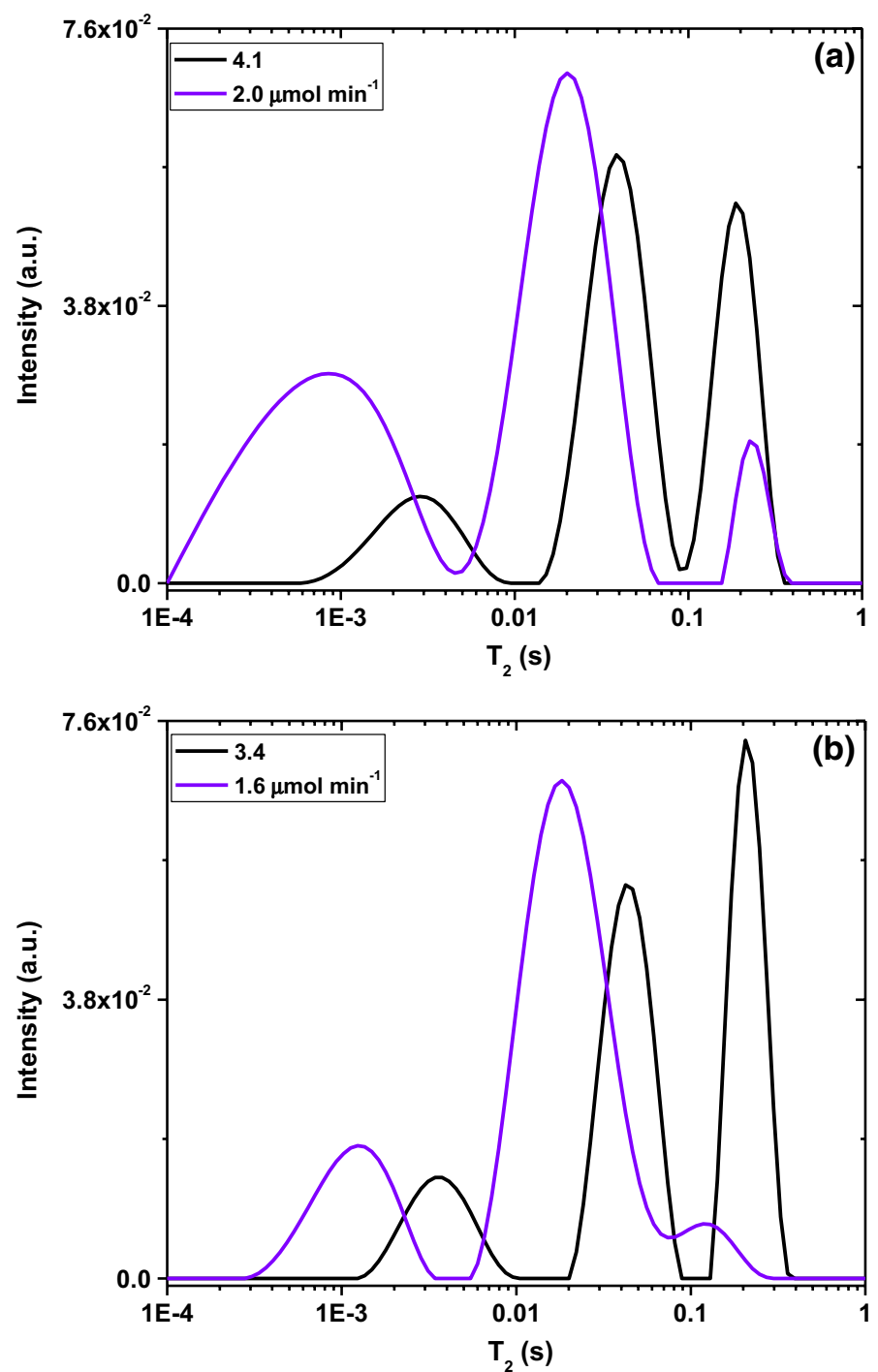

Fig. 3 Transverse relaxation time $\left(T_{2}\right)$ distribution for the CPMG signals calculated with inverse Laplace transform for a non-refrigerated (N) and b refrigerated (R) samples for times 0 and $72 \mathrm{~h}$

was similar to that of the $\mathrm{N}$ samples with similar PA, i.e., with the increase in the intensities of the peaks with shorter relaxation times, for samples with lower PA, as shown in Fig. $3 b$.

The potential of TD-NMR for measuring the enzymatic activity of cassava roots using a minimum sample preparation method was evaluated using multivariate PLS models. The total signals were from 6 fractions $\times 6$ samples $\times 4$ exposure times for 
non-refrigerated samples $(n=144)$ and 6 fractions $\times 3$ samples $\times 4$ exposure times for refrigerated samples $(n=72)$. The first model was built with CPMG signals up to $0.9 \mathrm{~s}$ (1500 independent variables) from $\mathrm{N}$ and $\mathrm{R}$ samples with the entire matrix data, with a total of 216 signals. The CPMG and PA data from $\mathrm{N}$ and $\mathrm{R}$ contributed 112 and 61 samples, respectively, for the training set and 43 samples for the validation set (32 for $\mathrm{N}$ and 11 for $\mathrm{R}$ ). The information of three latent variables (LVs) explained almost $100 \%$ of the variance from the training set using leave-one-out cross-validation.

Figure 4a, b shows the PLS regression model of the training and validation datasets. The reference values were obtained using a standard biochemical assay that was correlated with CPMG signals for the PLS models. The validation set comprised samples that were not included in the training data. As also verified, a notable result was the same magnitude of standard errors of cross-validation (SECV) and of prediction (SEP) for the sets, which indicates that the models are very promising for the prediction of PA.

Two other models were constructed for samples $\mathrm{N}$ and $\mathrm{R}$, considering their differences in the magnitude of enzymatic activity (Fig. 5). For this case, a selection of variables was also performed considering the first 319 independent variables, from 0 to 0.19 s of CPMG signals, with approximately $100 \%$ of explained variance using 3 LVs. This selection of variables was based on the evidence that after $0.19 \mathrm{~s}$, the signal response has low values of almost zero that did not contribute to the model. The data were highly correlated $(r=0.9)$ for the non-refrigerated set and the SECV with the same values reported for the previous model, as shown in Fig. 5a. The external samples showed slight differences considering the correlation and SEP, as can be verified in Fig. 5b. The model including the entire profile of CPMG decays showed the same magnitude of errors.

The noteworthy result was for the refrigerated samples using a model with 360 independent variables from 0 to $0.22 \mathrm{~s}$ and the same above-mentioned criteria for variable selection. Figure $6 \mathrm{a}, \mathrm{b}$ shows that the models confirmed the high correlation of both datasets with a low magnitude for SECV and SEP equal to $0.3 \mu \mathrm{mol}$ $\min ^{-1}$ for both parameters, using $4 \mathrm{LVs}$, with approximately $100 \%$ of explained variance.

In the case of the separate models for $\mathrm{N}$ and $\mathrm{R}$, the errors showed different magnitudes due to the differences in ranges for PA. To select the better model, the figures of merit for the PLS models were calculated [15], and Table 1 summarizes the lowest limit of detection (LOD) and limit of quantification (LOQ) for the global model with both type of samples. These results show that the model with all samples ( $\mathrm{N}$ and $\mathrm{R}$ ) has a greater potential to predict enzymatic activity in cassava roots than the individual models constructed for either $\mathrm{N}$ or R samples.

\section{Conclusions}

CPMG signals were able to verify variations in PA for both types of cassava roots, such as non-refrigerated roots and those industrialized refrigerated. In addition, 

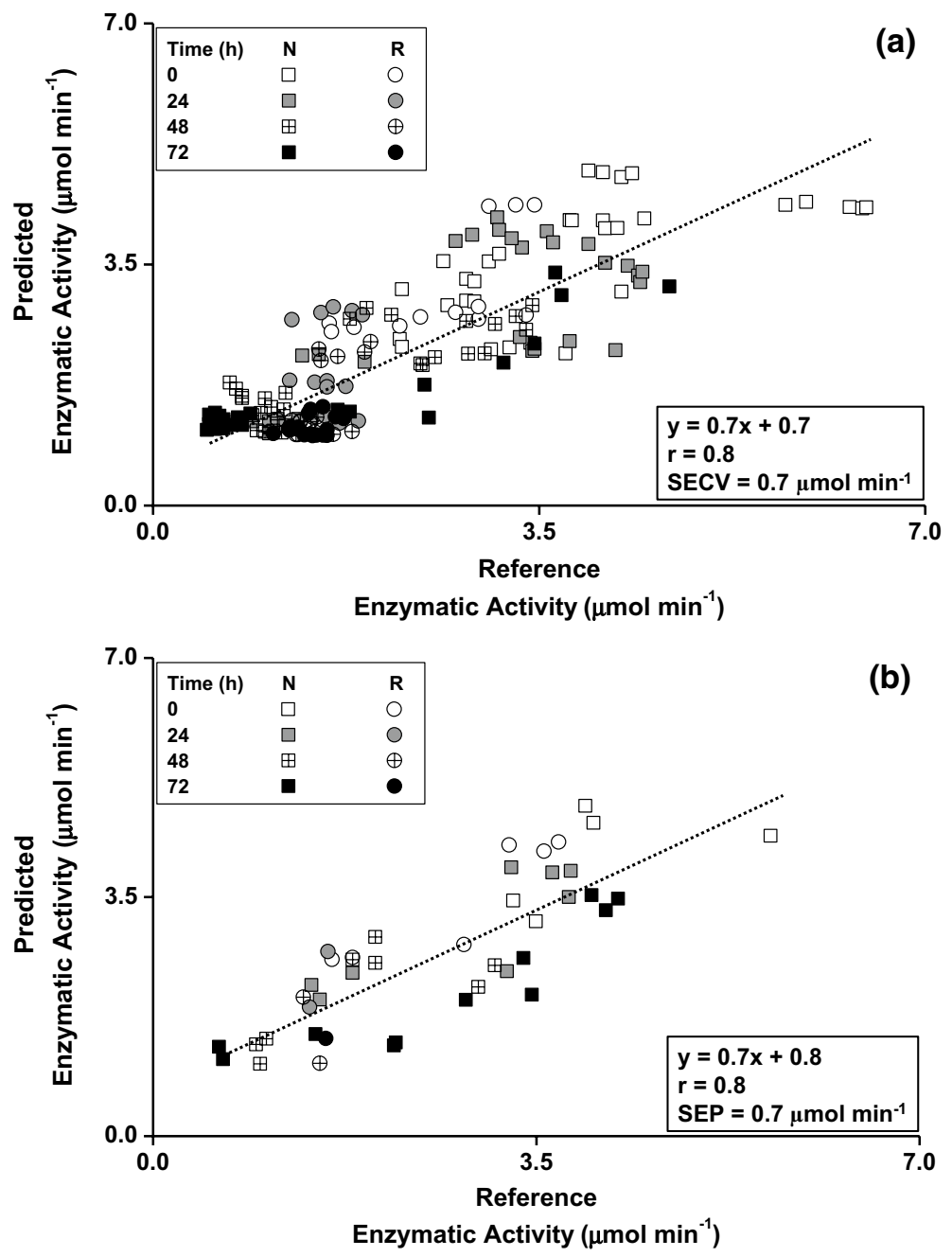

Fig. 4 Correlation between reference values from a standard biochemical assay to predict the enzymatic activity of peroxidase and predicted values using TD-NMR signals and partial least squares (PLS) algorithm for a global model with non-refrigerated $(\mathrm{N})$ and refrigerated $(\mathrm{R})$ samples for the a training and $\mathbf{b}$ validation datasets, calculated with 1500 independent variables

variations in PPD were also monitored upon exposure of the samples to air. This evidence was supported using the calculations of inverse Laplace transform for the decays. 

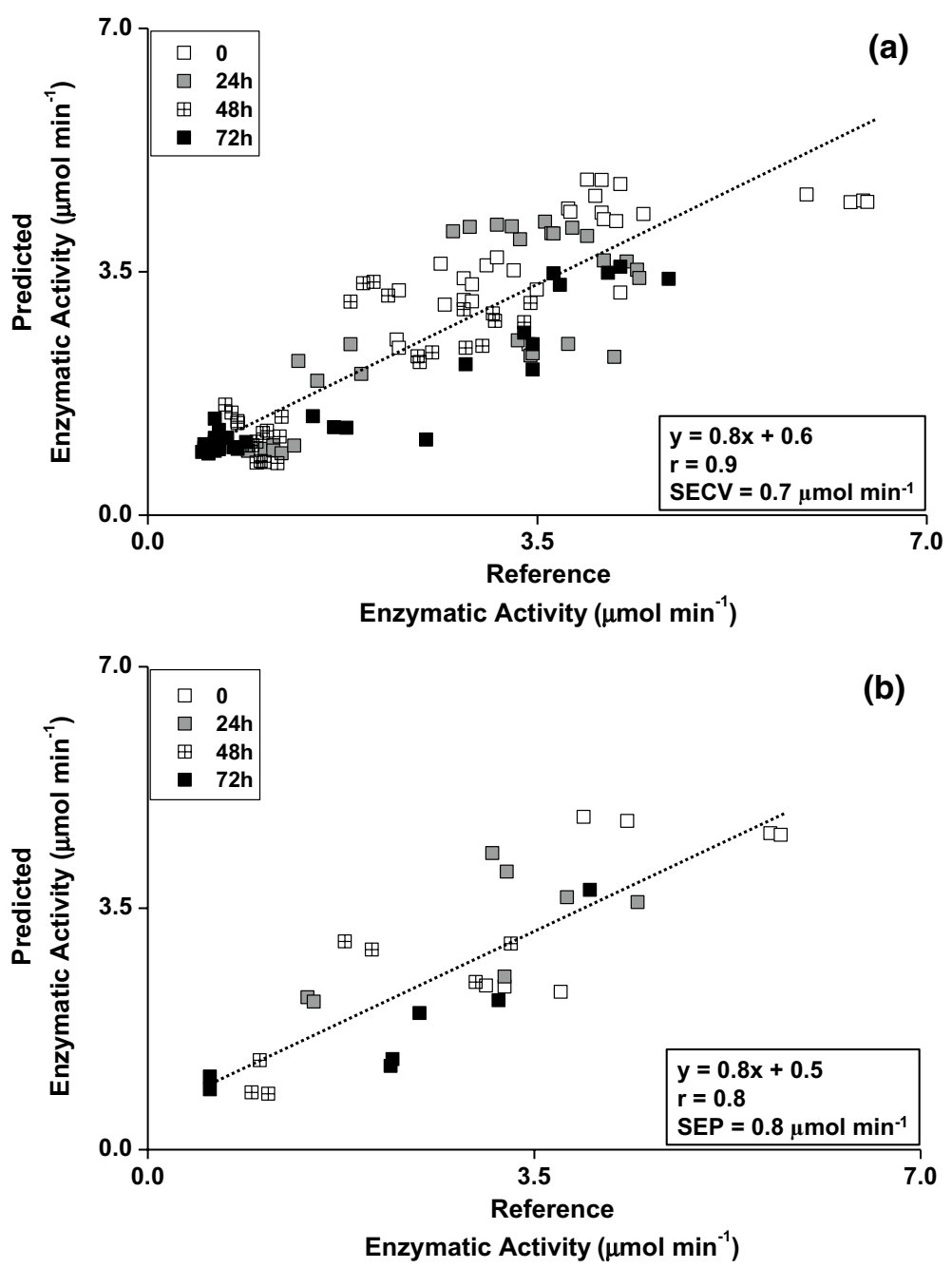

Fig. 5 Correlation between reference values from a standard biochemical assay to predict enzymatic activity of peroxidase and predicted values using TD-NMR signals and partial least squares (PLS) algorithm for non-refrigerated $(\mathrm{N})$ samples for the $\mathbf{a}$ training and $\mathbf{b}$ validation datasets, calculated with 319 independent variables

The model with either samples ( $\mathrm{N}$ and $\mathrm{R}$ ) was shown to be promising for the prediction of the enzymatic activity of peroxidase, with low standard errors and good indexes for figures of merit. Furthermore, this method will minimize the use of chemical reagents and accelerate this parameter in solid foods with high water contents. 


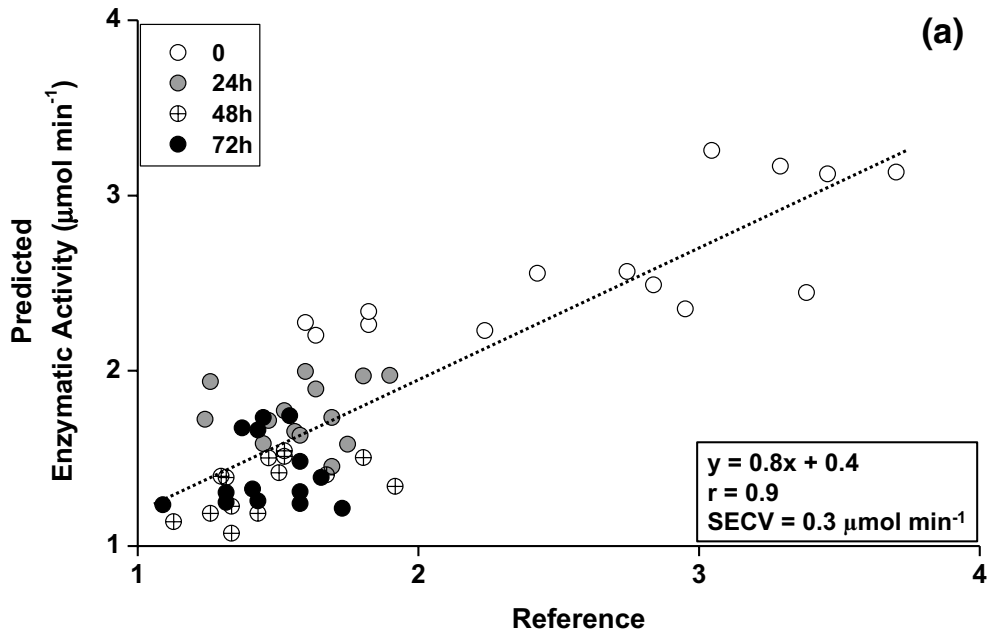

Enzymatic Activity ( $\left.\mu \mathrm{mol} \mathrm{min}^{-1}\right)$

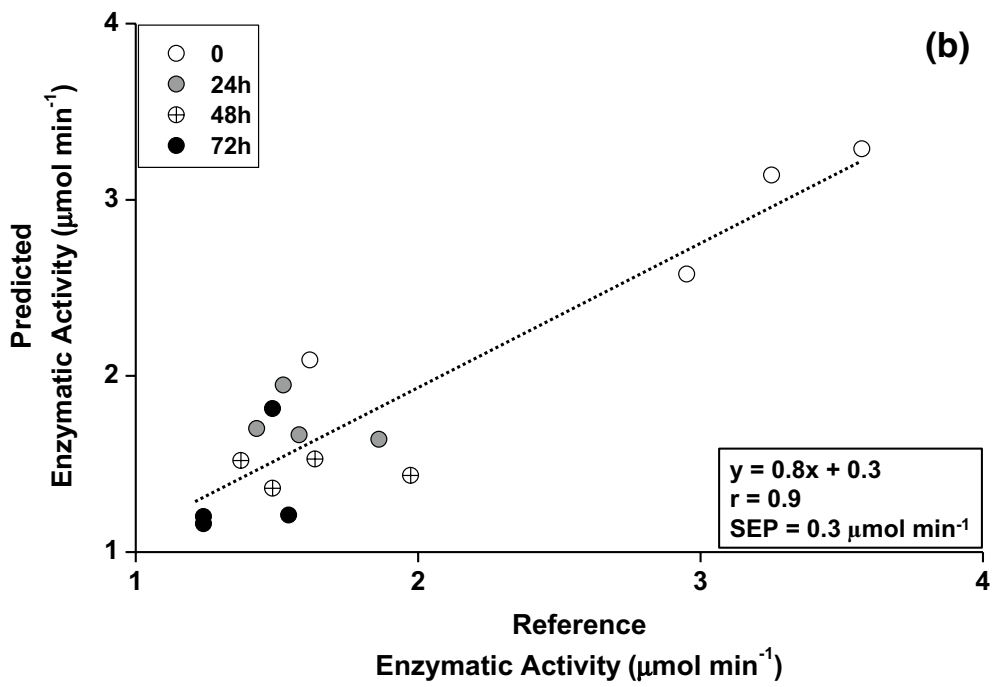

Fig. 6 Correlation between reference values from a standard biochemical assay to predict enzymatic activity of peroxidase and predicted values using TD-NMR signals and partial least squares (PLS) algorithm for refrigerated (R) samples for the a training and $\mathbf{b}$ validation datasets, calculated with 360 independent variables 


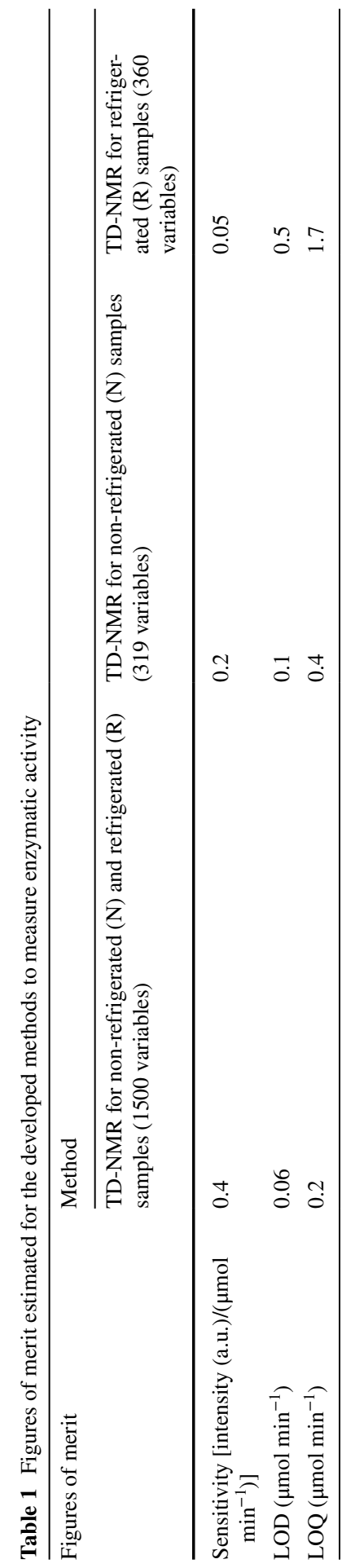


Acknowledgements This study was funded by the São Paulo Research Foundation (FAPESP, 2016/00779-6 and 2017/12864-0), the National Council for Scientific and Technological Development (CNPq, 445729/2014-7 and 303837/2013-6) and the Coordination for the Improvement of Higher Education Personnel (CAPES, J.S.F. Grant fellowship).

\section{References}

1. E. Kirtil, S. Cikrikci, M.J. McCarthy, M.H. Oztop, Curr. Opin. Food Sci. 17, 9 (2017)

2. J. van Duynhoven, A. Voda, M. Witek, H. Van As, Annu. Rep. NMR Spectrosc. 69, 145 (2010)

3. P.S. Belton, A.M. Gil, G.A. Webb, D. Rutledge, F. Cornejo, P. Chinachoti, in Magnetic Resonance in Food Science: Latest Developments, ed. by P.S. Belton, A.M. Gil, G.A. Webb, D. Rutledge (The Royal Society of Chemistry, Cambridge, 2003), pp. 25-37

4. L.A. Colnago, F.D. Andrade, A.A. Souza, R.B.V. Azeredo, A.A. Lima, L.M. Cerioni, T.M. Osán, D.J. Pusiol, Chem. Eng. Technol. 37, 191 (2014)

5. B. Blümich, Trends Anal. Chem. 83, 2 (2016)

6. V.G. Uarrota, M. Maraschin, BMC Res. Notes 8, 648 (2015)

7. V.G. Uarrota, E.C. Nunes, L.A.M. Peruch, E.O. Neubert, B. Coelho, R. Moresco, M.G. Domínguez, T. Sánchez, J.L.L. Meléndez, D. Dufour, H. Ceballos, L.A.B. Lopez-Lavalle, C. Hershey, M. Rocha, M. Maraschin, Food Sci. Nutr. 4, 409 (2016)

8. I.M. Zainuddin, A. Fathoni, E. Sudarmonowati, J.R. Beeching, W. Gruissem, H. Vanderschuren, Postharvest Biol. Tec. (2017). https://doi.org/10.1016/j.postharvbio.2017.09.004

9. R.H. Howeler (ed.), The Cassava Handbook. A Reference Manual Based on the Asian Regional Cassava Training Course held in Thailand. Centro Internacional de Agricultura Tropical (CIAT) (2011)

10. V.G. Uarrota, R. Moresco, E.C. Schmidt, Z.L. Bouzon, E.C. Nunes, E.O. Neubert, L.A.M. Peruch, M. Rocha, M. Maraschin, Food Chem. 197, 737 (2016)

11. F.M.V. Pereira, S.B. Pflanzer, T. Gomig, C.L. Gomes, P.E. de Felício, Talanta 108, 88 (2013)

12. C.C. Lin, C.H. Kao, Plant Soil 216, 147 (1999)

13. M. Daszykowski, B. Walczak, D.L. Massart, Anal. Chim. Acta. 468, 91 (2002)

14. J.A. Troller, J.H.B. Christian, Water Activity and Food (Academic Press Inc., New York, 1978)

15. F.M.V. Pereira, E.R. Pereira-Filho, M.I.M.S. Bueno, J. Agric. Food Chem. 54, 5723 (2006) 